\title{
Hypochondriacal Anxieties in Adolescence
}

\author{
Stelios Christogiorgos, Dimitris Tzikas, Marie-Ange Widdershoven-Zervaki, Panagiota \\ Dimitropoulou, Eftychia Athanassiadou and George Giannakopoulos*
}

\author{
Department of Child Psychiatry, Athens University Medical School, Aghia Sofia Children's Hospital, Thivon and \\ Papadiamantopoulou, Athens 11527, Greece
}

\begin{abstract}
Hypochondriasis is one of the most characteristic psychopathological entities related to the disturbance of the body image, which is the result of complicated identifications with damaged internal objects. Transient hypochondriacal states frequently appear during periods of huge changes, such as phases of bodily growth. They often manifest themselves in adolescence which is the most favourable period for them to appear. The bodily part or function that has changed, and which was initially experienced as threatening or foreign, needs time and experience to become integrated into the total representation of the body. A case example is presented here and implications for child psychotherapy are discussed.
\end{abstract}

Keywords: Adolescence, Anxiety, Hypochondriasis, Psychoanalysis.

\section{INTRODUCTION}

In Freud's essay on narcissism, it is assumed that hypochondriacal anxieties are raised in connection to the Ego's libido, just as neurotic anxieties are raised in connection to the object's libido [1,2]. The two integral parts of the disorder, psychic and somatic, led Freud [3] to the discovery that hypochondriasis could be regarded as a third "actual" neurosis. Freud [4] had already introduced for the first time the term "actual neurosis"; he included anxiety neurosis and neurasthenia under this category. In the current diagnostic classifications hypochondriasis is categorized in the somatoform disorders both in the fourth edition of the Diagnostic Statistical Manual of Mental Disorders (DSM-IV) [5] under the code \#300.7 and in the tenth edition of the International Classification of Diseases (ICD-10) [6] under the code \#F45.21. In fact, the ICD-10 recognizes a broader category of hypochondriacal disorders (\#F45.2) including unspecified hypochondriacal disorders, hypochondriasis, body dysmorphic disorder, and other hypochondriacal disorders.

Schilder [7] showed intense interest in this disorder and he noted the similarities between hypochondriasis and depersonalization. He supports that the hypochondriacal fixation belongs to the narcissistic phase because it is a fixation in a very early stage of the development of the body image, which is affected not only by bodily sensations but also by the infant's oral, sadistic, and sadomasochistic drives, since pain constitutes a significant part in the whole process. Freud [2] indicates that the way in which we acquire new knowledge regarding our bodily organs during painful illnesses is perhaps a model of the way in which we generally form our

*Address correspondence to this author at the Department of Child Psychiatry, Athens University Medical School, Aghia Sofia Children's Hospital, Thivon \& Papadiamantopoulou, Athens 11527, Greece;

Tel/Fax: 00302107473811; E-mail: giannakopoulos.med@gmail.com body image. On the same subject, Schilder [7] assumes that pain proffers an incentive both for a sadistic-anal and a narcissistic regression that also includes the use of magical thought. Schilder was amongst those who dealt extensively with this disorder. In his theory on hypochondriasis, he describes a model based on an augmented narcissistic libido. This leads to a process whereby the organ that supposedly suffers from something represents, on a symbolic plane, a forgotten desire, usually one of sexual content. Schilder [7] also stresses that what needs to be taken into serious consideration is the particular psychic quality of the hypochondriacal organ which, more often than not, is a symbol of the genitalia.

Melanie Klein [8], expanded our understanding of hypochondriasis even further, stressing the fact that in narcissistic phases (hypochondriasis is included in them), libidinal and aggressive drive impulses are attached to the good and the bad objects inside the Ego. According to Klein, the basis of hypochondriasis is formed by the anxiety which is related to the aggressive drive impulses which attack the internalized objects (internal representations of the parents). Sadistic fantasies mobilize anxieties and fears related to the fact that a person recoils in horror at the idea that there are persecuting bad objects, inside his body, which poison him. The appearance of hypochondriacal fears follows the same process.

Anna Freud [9] explored the development of hypochondriacal anxieties in orphan children. She concluded that these children identify with the lost mother, while the body represents the infant in the mother's care. "The child actually deprived of a mother's care adopts the mother's role in health matters, thus playing 'mother and child' within his own body".

In hypochondriasis the unconscious guilt over libidinal and aggressive wishes, fantasies, and feelings must be dis- 
guised to avoid overwhelming the self with fears of retaliatory punishment, bodily castration and death [10]. Hypochondriacal patients use various mature and immature defense mechanisms to overcome these anxieties.

Apart from psychoanalytic approach, cognitive-behavioral models have been developed in order to understand the pathogenesis of hypochondriasis. Emphasis has been given on patients' tendency to misinterpret bodily symptoms, bodily variations, and other health-related information indicating a serious physical illness. In particular, hypochondriacal individuals overestimate the probability of serious illnesses and perceive bodily symptoms as more dangerous than they actually are [11]. Also, the cognitive developmental model proposed by Williams [12] gives emphasis on neuroticism which is described as the behavioral manifestation of an individual that focuses on incidents including punishment or threat. This selective attention to threat can be transformed to various bodily sensations and health threats for people with hypochondriacal tendencies. Other social developmental factors considered as responsible for the maintenance of hypochondriasis are the following: a) prior experience with illness during childhood, b) learning experience e.g. through parents' modelling, and c) attachment difficulties.

\section{TYPES OF HYPOCHONDRIASIS}

Herbert Rosenfeld [13] put forward his contribution to understand the disorder on the following assumptions: a) hypochondriasis is the result of complicated identifications with damaged internal objects, b) the damage has been caused by projective identification, c) it stems from sadistic oral envy, and d) it generates a confusion between self and object. Furthermore, the hypochondriacal state manifests itself as a defense mechanism against the confusing state between depressive anxieties and paranoid persecutory anxieties. The hypochondriacal patient constantly projects parts of their psychic and somatic self upon the external objects and the main characteristic of this disorder is that, after the projection, the external object is immediately reintrojected by the Ego and breaks down into small pieces in the body and its organs.

The type of hypochondriasis mentioned above is based on projections onto the outer world, resulting in delusional ideas about the body. It is a delusion of self-reference towards the outside world which results in hypochondriacal ideas about the body. In the case of the somatic delusion, social relations are being severely disturbed and lead the patient to isolation, since they think that they are watched, that everybody looks at them and everybody picks on their body defect. During the somatic delusion, there exists a splitting of the self and this split-off part takes hold of the body. The split-off part exists independently, alien from the Ego and interferes with the good object relationships. In an attempt to incorporate the part that has been split-off, the somatic delusion re-appears.

Another type of hypochondriasis, as described in detail by David Rosenfeld [14], is based mostly on autistic mechanisms; it is more silent, chronic, and more rigid. One might assume that it is the type that corresponds to the chronic form of the disorder. Here, the hypochondriacal core has very little interaction with the external world. The patient creates a rigid defense in which the conflict with the object becomes encapsulated in some part of the body, similarly to what we can observe in autistic children. This encapsulated part is often experienced as foreign, non-Ego territory. The patient functions as an autistic child (with their autistic objects) and retreats to their own world of sensations. Unlike the first type of hypochondriasis in which the patient experiences their body as containing blood, muscles and sometime skin, the autistic hypochondriacal experiences their body as empty and hollow.

A third type is predominantly based on a psychoticprimitive body scheme. These patients, having lost the psychological notion of the skin, feel that their body scheme is a vital fluid, sometimes conceptualized as blood, contained only by a weak membrane or wall. Hypochondriacal notions regarding the psychotic primitive body scheme can be found in patients who unfoundedly believe that they suffer from leukaemia or haemophilia. According to David Rosenfeld [14], hypochondriasis centred on a psychotic body image should alarm us, as it implies the danger of accidents or suicide attempts. He also suggests that it is not only the danger of a suicidal attempt that we should be cautious about, but drug use as well, something quite common in adolescence, where the primitive-psychotic body scheme can predominate.

These different types of hypochondriasis are not preset and static. Oftentimes some of the patients start off with a delusional idea about their body, then they develop more chronic hypochondriasis, and they end up with the type of hypochondriasis based on the psychotic-primitive body scheme saying, for example, that they suffer from haemophilia or that they are in danger of dying from profuse haemorrhage.

\section{HYPOCHONDRIACAL ANXIETIES IN ADOLES- CENCE}

Transient hypochondriacal states frequently appear during periods of huge changes, such as phases of bodily growth [14]. They often manifest themselves in adolescence which is the most favourable period for them to appear. As Winnicott [15] indicates, the internal representation of our body is a combination of everything that our senses perceive, everything that originates from our actual body, all the things that the external stimuli cause us to imagine, and everything we fantasize about our body. The adolescent is at a stage of development during which the sensory stimuli that derive from the actual body are consecutive and fresh [16].

In adolescence, the body continuously changes both in size and in structure. The adolescent, self-conscious and scared, watches his body and its functions change day by day, month by month. Nothing is the same as it was yesterday. Concerns and questions come to the surface. "Is there something wrong with my arms, my growing legs, my blossoming breast?” The adolescent is under the internal pressure of the drives as well as under the internalized pressure provoked by the rapid changes of his body: "I am feeling new things, different, and my desires change every day. I even look at the people who surround me in a different light. Could it be that there is something wrong with my mind? Am I not normal, perhaps?”. Bodily parts and functions 
change rapidly and the adolescent identifies with the total representation of the body; yet, initially, the changing bodily parts, not being fully integrated, are experienced as hostile, harmful, and maybe foreign. The idealized body of childhood is threatened by the changes and the emerging sexuality. The infantile fantasy of fusion with the mother is threatened by the predominant oedipal problematic. The adolescent finds it difficult to integrate sex into his personality because this is initially very stressful for him; he could even have feelings of disgust towards it. Early infantile mechanisms and anxieties come to the fore. The Ego has a hard time dealing with the state of confusion because the good part of the self and the good internalized objects, on which its stability depends, are in constant danger of being overwhelmed by the bad part of the self and the bad internalized objects. At the same time, this means that the depressive anxiety that triggers the correctional process cannot function in order to alleviate the confusion. The Ego, still frail, finds it difficult to withstand the increased, all-mighty oral-sadistic drives, and the splitting mechanism is set in motion. Oral sadism and its derivatives undergo partial splitting and the part that becomes detached is first projected by the Ego upon external objects and then quickly re-introjected in the body and its organs. Furthermore, the adolescent may have delusional ideas about his body, which severe his social relationships, since he may think that he is being watched and that everybody looks at his "body defect".

In adolescence, this process is dynamic and it is part of the development, it is not consolidated. The bodily part or function that has changed, and which was initially experienced as threatening or foreign, needs time and experience to become integrated into the total representation of the body. This process comes into being at the end of adolescence.

\section{CASE EXAMPLE}

An example of the changing process of hypochondriacal state during adolescence can be seen in the following case.

Alex was 16 years old when he was referred for psychotherapy. It was reported that in the recent months he was isolating himself from his friends. He had difficulty in concentrating on his studies, which was very upsetting for him since he was in the process of undertaking his entry exams for the University, process which required a lot of reading and concentration. However, all of his records at school exams were excellent.

Alex presented with various fears. If he would see a dog while walking, he believed that he would be beaten. He would immediately start to search his legs trying to locate the supposed wounds. This behaviour was accompanied with a lot of distress and could last for hours or even days. If he happened to pass by a bin he believed that there were flown broken glasses which would come towards his face. At certain times, he believed that the broken glasses entered his mouth and he swallowed them. He was agonizing in many occasions thinking that the broken glasses would mortally wound his gut.

Alex is the first child of the family. He has two siblings: a brother and a sister. His parents are from high socioeconomic class. He described his father as particularly com- petitive towards him; all their conversations used to end up in an argument. His father was never satisfied with the achievements of his son, although Alex was one of the best students in his class. His mother was described as cold and distant and he could not remember if she has ever embraced or caressed him; while she could very easily criticise him for his actions.

In his psychotherapy treatment, he was very punctual and consistent. He had the tendency to use concrete description of his fears despite the efforts of the therapist to direct him to the emotional experience of his relationships. In the course of treatment, he showed improvement in the quality of his life but also change in his symptomatology. His anxiety was considerably decreased and he was capable, when he was calm, to be focused on his relationships and the emotions they were causing him. He began to create bonds with his schoolmates and he was maintaining them for long intervals. He also progressed in his study.

While initially his symptom were the fear of dogs and a more general feeling of threat from his environment, in the course of the treatment these receded and they were replaced by an obsessive interest in his body. Main focus of his attention was the moles of his skin and his heart. He would look at his moles for hours trying to understand if there was any pathological change. Other times he was worried a lot about his heart; he was continuously checking his pulse, complaining of pain in his heart and he was afraid that he will suffer cardiac infarction with the least effort. He was avoiding going up the scales and he limited his gymnastics class that he was previously attending daily. His fears were intensified excessively in the periods of intense stress, either in relation to his relationships or his study.

His transference was expressed mainly in two directions. He was seeking for confirmation and reassurance regarding his fears, trying to obtain this mainly in indirect ways. On the other hand, he would react by disputing, with intensity, the comments of his therapist, while "admitting" them in his free associations. His transference tendencies reflected the central axes of his relationship with his parents. When the distress he was experiencing was intense, he used to telephone his parents trying to get the reassurance regarding his fears. On the other hand he reacted very intensely on their every comment or discussion experiencing this as an effort of imposition and control on him.

The continuation of the treatment and the progressive emerging of the good internal structure have reduced his internally projected persecutory anxiety and his hypochondriacal symptomatology. Towards the end of his therapy, his hypochondriacal manifestations were present only during the periods of intense emotional distress.

\section{CONCLUSION}

Cognitive-behavioral therapy has received some empirical support for hypochondriasis, with its core components including: a) assessment and engagement, b) reaching a shared understanding, c) self-monitoring, d) identification and re-attribution of negative automatic thoughts, e) modification of maintaining factors, f) identification and reattribution of dysfunctional assumptions, and g) relapse pre- 
vention [17]. Also, one randomized clinical trial by Sørensen et al. [18] showed that a cognitive-behavioral programme was superior in treating hypochondriasis compared to short term psychodynamic psychotherapy. Nevertheless, follow-up studies are necessary to examine the longer term efficacy of the approach and which of the components of cognitivebehavioral treatment are most effective. Especially, in the case of difficult medical patients, who may be more reluctant to consider psychological treatment, further research is needed [17].

Most hypochondriacal patients who require therapeutic intervention lack insight, or in more analytic terms, lack an "observing ego". The psychodynamic approach provides valuable information through the uncovering process of the psychological antecedents of hypochondriasis and by exploring the defense mechanisms of the patients. This exploration is crucial for the therapeutic procedure, since it plays an important role in the selection of the appropriate level of intervention. In adolescence, when premature defense mechanisms, such as splitting and projection, prevail, psychotherapy initially focuses, mainly on the external relationships of the patient and on their internal defense procedures; more emphasis is given to the logical aspects of these mechanisms and less to the emotional ones. Gradually, after establishing therapeutic alliance focus can be given to the deeper meaning of the defense mechanisms and the transference phenomena that evolve in the relationship between the therapist and the patient. The aim of the therapy is bridging the gap between the persecuting and the idealized parts of the internal objects in order to reduce the mechanisms of splitting and projection. Above all, no single approach can provide adequate explanations about the complex symptoms and interconnections underlining hypochondriasis. One may not preclude another even when their respective language may differ.

\section{CONFLICT OF INTEREST}

The author(s) confirm that this article content has no conflicts of interest.

\section{ACKNOWLEDGEMENT}

None declared.

\section{REFERENCES}

[1] Crockatt P. Freud's 'On narcissism': An introduction. J Child Psychother 2006; 32: 4-20.

[2] Freud S. On Narcissism. London: The Hogarth Press 1914.

[3] Freud S. Contributions to a discussion on masturbation. London: The Hogarth Press, 1912.

[4] Freud S. Sexuality in the etiology of neuroses. London: The Hogarth Press 1898.

[5] American Psychiatric Association. Diagnostic and statistical manual of mental disorders - DSM-IV. $4^{\text {th }}$ ed. Washington, DC: American Psychiatric Association 1994.

[6] World Health Organization. ICD-10: International statistical classification of diseases and related health problems. New York: World Health Organization 2008.

[7] Schilder P. The image and appearance of the human body. New York: International Universities Press 1978.

[8] Klein M. Mourning and its relation to manic-depressive states. Int J Psychoanal 1940; 21: 125-53.

[9] Freud A. The role of bodily illness in the mental life of children. Psychoanal Study Child 1952; 7: 69-81.

[10] Starcevic V, Lipsett D, Eds. Hypochondriasis: modern perspectives on an ancient malady. New York: Oxford University Press 2001.

[11] Salkovskis PM, Warwick HC. Meaning, misinterpretations, and medicine: A cognitive-behavioral approach to understanding health anxiety and hypochondriasis. In: Starcevic V, Lipsitt DR, Eds. Hypochondriasis: modern perspectives on an ancient malady. New York: Oxford University Press 2001.

[12] Williams PG. The psychopathology of self-assessed health: a cognitive approach to health anxiety and hypochondriasis. Cognit Ther Res 2004; 28(4): 629-44.

[13] Rosenfeld H. Some observations on the psychopathology of hypochondrial states. Int J Psychoanal 1958; 39: 121-4.

[14] Rosenfeld D. Hypochondrias, somatic delusion and body scheme in psychoanalytic practice. Int J Psychoanal 1984; 65: 377-87.

[15] Winnicott D. The maturational processes and the facilitating environment. London: Hogarth Press and the Institute of Psychoanalysis 1965.

[16] Winnicott D. Basis for self in body. Int J Child Psychother 1972; 1: 7-16.

[17] Allen LA, Woolfolk RL. Cognitive behavioral therapy for somatoform disorders. Psychiatr Clin North Am 2010; 33(3): 57993.

[18] Sørensen P, Birket-Smith M, Wattar U, Buemann I, Salkovskis P. A randomized clinical trial of cognitive behavioural therapy versus short-term psychodynamic psychotherapy versus no intervention for patients with hypochondriasis. Psychol Med 2011; 41(2): 43141.

Received: March 10, 2013

Revised: May 09, 2013

Accepted: May 27, 2013

(c) Christogiorgos et al.; Licensee Bentham Open.

This is an open access article licensed under the terms of the Creative Commons Attribution Non-Commercial License (http://creativecommons.org/licenses/ by-nc/3.0/) which permits unrestricted, non-commercial use, distribution and reproduction in any medium, provided the work is properly cited. 